\title{
Mg-Mn (Magnesium-Manganese)
}

\section{H. Okamoto}

[Massalski2] shows only a partial phase diagram on the Mg-rich side (0-3 at.\% Mn) accepted from [1985Nay].

Figure 1 shows the complete $\mathrm{Mg}-\mathrm{Mn}$ phase diagram obtained by DTA measurements and thermodynamic calculations by [2005Gro]. [2009Asg] obtained a very similar result also by thermodynamic calculations.

\section{References}

1985Nay: A.A. Nayeb-Hashemi and J.B. Clark, The Mg-Mn (Magnesium-Manganese) System, Bull. Alloy Phase Diagr., 1985, 6(3), p 238-244
2005Gro: J. Gröbner, D. Mirkovic, M. Ohno, and R. SchmidFetzer, Experimental Investigation and Thermodynamic Calculation of Binary Mg-Mn Phase Equilibria, J. Phase Equilib. Diffus., 2005, 26(3), p 234-239

2009Asg: $M$. Asgar-Khan and $M$. Medraj, Thermodynamic Description of the Mg-Mn, Al-Mn, and Mg-Al-Mn Systems Using the Modified Quasichemical Model for the Liquid Phase, Mater. Trans., 2009, 50(5), p 1113-1122

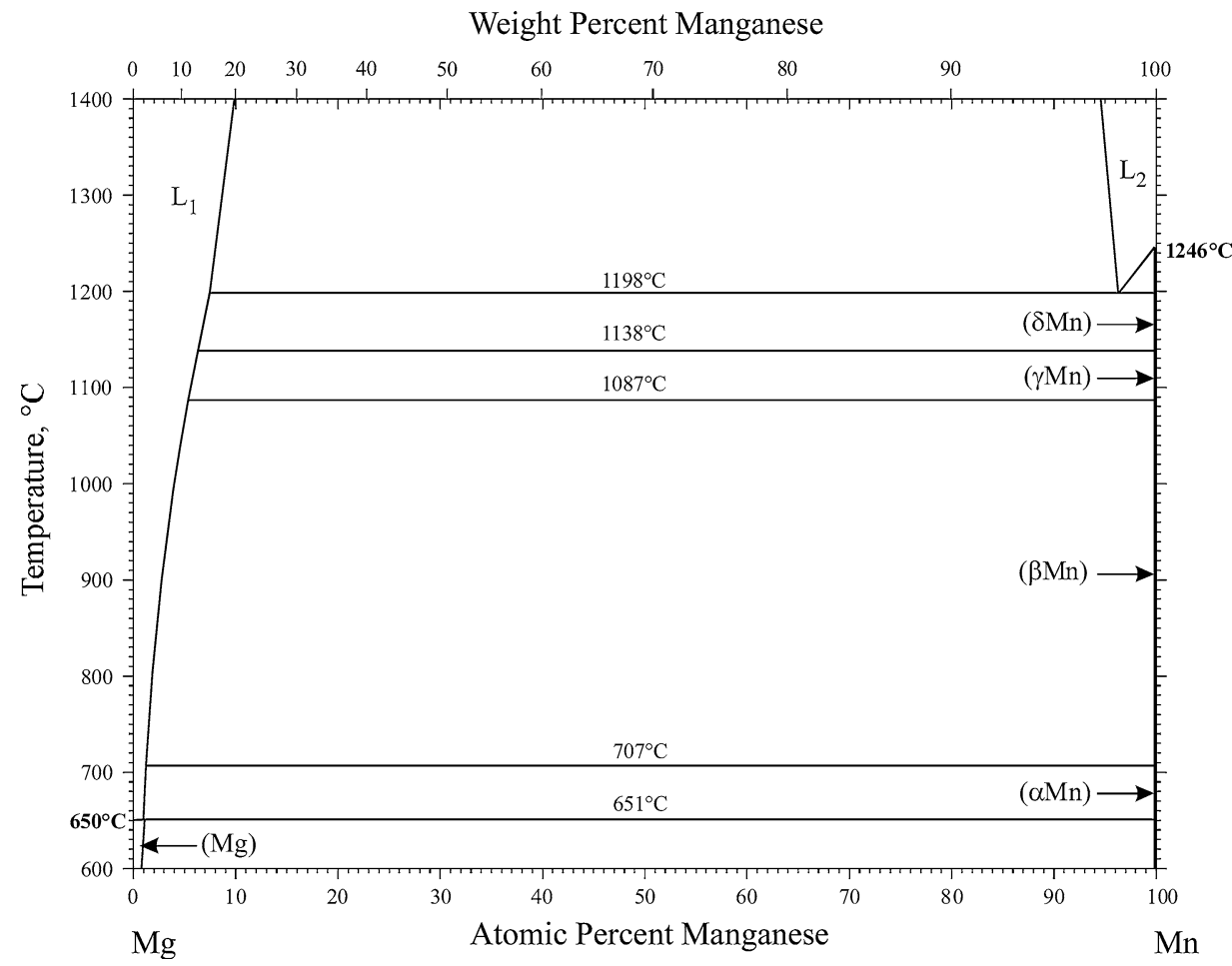

Fig. 1 Mg-Mn phase diagram 